\title{
O significado da pesquisa em Comportamento Animal ${ }^{1}$
}

\author{
Charles T. Snowdon
}

Universidade de Wisconsin

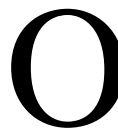
estudo do Comportamento Animal é uma ponte entre os aspectos moleculares e fisiológicos da biologia e da ecologia. O comportamento é a ligação entre organismos e o ambiente, e entre o sistema nervoso e o ecossistema. O comportamento é uma das propriedades mais importantes da vida animal. $\mathrm{O}$ comportamento tem um papel fundamental nas adaptações das funções biológicas. O comportamento é como nós definimos nossas próprias vidas. O comportamento representa a parte de um organismo através da qual ele interage com o ambiente. O comportamento é parte de um organismo tanto quanto sua pele, suas asas etc. A beleza de um animal inclui seus atributos comportamentais.

Pelas mesmas razões que nós estudamos o universo e as partículas subatômicas, há também o interesse intrínseco no estudo dos animais. Considerando-se a quantidade de tempo que a televisão devota aos filmes de animais e a quantidade de dinheiro que as pessoas gastam em livros sobre a natureza, é de acreditar que há maior interesse da opinião pública em Comportamento Animal do que em nêutrons e neurônios. Se a curiosidade humana direciona pesquisas, o estudo do Comportamento Animal deveria estar próximo do topo de nossas prioridades. 
A pesquisa em Comportamento Animal e Ecologia Comportamental tem avançado nos últimos anos a despeito dos baixos investimentos (e, freqüentemente, redução) na pesquisa. Dois de nossos periódicos, Animal Behavior e Behavior Ecology and Sociobiology, estão localizados entre os seis primeiros no ranking dos periódicos de Ciência Comportamental e de Zoologia, em termos de impacto medido pelo Science Citation Index. De 1985 a 1990, o periódico Animal Behavior cresceu de quatro números/ano para uma periodicidade mensal e a quantidade de páginas mais que duplicou. Muitos periódicos correlatos aumentaram seu tamanho e freqüência de publicações no mesmo período. Nosso campo de estudo é ativo e vital.

O estudo do Comportamento Animal não é um importante campo científico apenas por si próprio, mas também por ter feito importantes contribuições para outras disciplinas com aplicações para o estudo do comportamento humano, para as neurociências, para o manejo do meio ambiente e de recursos naturais, para o estudo do bem-estar animal e para a educação de futuras gerações de cientistas.

\section{Comportamento Animal e sociedade humana}

1. Muitos problemas da sociedade humana estão freqüentemente relacionados a interações entre ambiente e comportamento ou entre genética e comportamento. As áreas da Socioecologia e do Comportamento Animal lidam com a questão das interações comportamentais e do ambiente, tanto do ponto de vista imediato, quanto do evolutivo. Um número crescente de cientistas sociais tem recorrido ao Comportamento Animal como uma base teórica para interpretar a sociedade humana e para entender possíveis causas de problemas das sociedades (e.g., o livro de Daly e Wilson sobre homicídio é baseado em uma análise evolutiva derivada da pesquisa com animais. Muitos estudos sobre abuso infantil utilizam a teoria e dados de estudos de infanticídio em animais).

2. Uma pesquisa realizada por de $\mathrm{Waal}^{2}$ ilustra a importância da cooperação e reconciliação em grupos sociais de chimpanzés e ou- 
tros macacos. Este trabalho fornece novas perspectivas para a análise e o tratamento do comportamento agressivo em humanos.

3. A metodologia utilizada no estudo do Comportamento Animal tem tido um tremendo impacto na Psicologia e nas Ciências Sociais. Jean Piaget iniciou seus estudos trabalhando com caramujos e, posteriormente, estendeu o uso de observações e de descrições comportamentais cuidadosas para seus famosos estudos sobre o desenvolvimento da cognição humana. J. B. Watson iniciou seus estudos do comportamento observando gaivotas. Vários aspectos de planejamentos experimentais, de técnicas de observação, a atenção a sinais na comunicação não-verbal foram muitas vezes desenvolvidos em estudos do Comportamento Animal, antecedendo sua aplicação a estudos do comportamento humano. O estudo comportamental de humanos seria muito reduzido hoje sem a influência da pesquisa do Comportamento Animal.

4. O trabalho de Charles Darwin sobre as expressões da emoção em animais teve uma influência muito importante sobre diversos psicólogos, como Paul Ekman, que estuda o comportamento emocional humano.

5. Os trabalhos de Harry Harlow sobre o desenvolvimento social de macacos Rhesus e os de Overmier, Maier e Seligman sobre o desamparo aprendido têm tido forte influência nas teorias de desenvolvimento infantil e na psiquiatria.

6. O estudo comparativo do comportamento com um leque amplo de espécies, pode fornecer insights sobre fatores que afetam o comportamento humano. Por exemplo, o muriqui (macaco do sudeste do Brasil) não apresenta agressão aberta entre os membros do grupo social. Nós podemos aprender como minimizar a agressão humana se nós compreendermos como esta espécie evita a agressão. Se nós queremos ter pais mais envolvidos no cuidado com os filhos, podemos estudar as condições nas quais o cuidado paterno apareceu em outras espécies, como o camundongo da Califórnia, sagüis e micos-leões. Estudos de vários modelos da ontogênese da comunicação em pássaros e mamíferos tiveram influência direta no desenvolvimento de teorias e no direcionamento de pesquisas no estudo da 
linguagem em crianças. A riqueza dos processos de desenvolvimento do comportamento animal, incluindo aí sua multideterminação e as conseqüências da experiência, é significativa na compreensão dos processos de desenvolvimento humano.

7. Entender as diferenças de adaptabilidade entre espécies que vivem em uma variedade de hábitats e aquelas que se restringem a hábitats limitados pode levar à compreensão de como nós podemos melhorar a adaptabilidade humana frente às variações do nosso ambiente.

8. Pesquisas realizadas por estudiosos do Comportamento Animal sobre os sistemas sensoriais animais levaram a aplicações práticas que expandiram o sistema sensorial humano. Demonstrações de Griffin, de como morcegos usam o sonar para localizar objetos, tiveram como consequiência direta o uso de técnicas com sonar em uma gama de aplicações, desde as militares até o diagnóstico fetal.

9. Estudo com chimpanzés usando análogos da linguagem levaram a novas tecnologias (teclado de computadores usando símbolos arbitrários), que têm sido aplicadas com sucesso ao ensino da linguagem para populações humanas desfavorecidas.

10. A pesquisa básica sobre ritmos circadianos e outros ritmos endógenos em animais motivou pesquisas relevantes sobre fatores humanos na produtividade, como por exemplo, os efeitos do jet-lag ou de mudanças de turnos.

11. A pesquisa com animais levou ao desenvolvimento de importantes conceitos relativos à adaptação ao estresse, como os estudos sobre a importância da previsibilidade e controle do indivíduo sobre o ambiente para lidar de forma adequada com o estresse.

\section{Comportamento Animal e Neurobiologia}

1. Sir Charles Sherrington, ganhador do prêmio Nobel, desenvolveu um modelo para a estrutura e função do sistema nervoso baseado somente em observações comportamentais e deduções. Setenta anos de pesquisas neurobiológicas subseqüentes corroboraram completamente as inferências de Sherrington a partir das observações comportamentais. 
2. A Neuroetologia, a integração do Comportamento Animal e das Neurociências, fornece bases teóricas importantes para a proposição de mecanismos neurais. Dados comportamentais cuidadosos permitem aos neurobiologistas direcionar seus estudos e focalizá-los sobre estímulos relevantes, selecionando respostas igualmente relevantes. Em muitos casos, o uso de estímulos espécie-específicos permitiu novos insights sobre a estrutura e função neurais que se contrapõem a resultados obtidos usando estímulos não-relevantes.

3. Trabalhos recentes sobre o Comportamento Animal têm demonstrado a influência do comportamento e da organização social sobre os processos fisiológicos e celulares. Variações no ambiente social podem inibir ou estimular ovulação, produzir sincronia menstrual ou induzir abortos. Outros estudos mostram que a qualidade do ambiente social e comportamental tem efeito direto sobre o funcionamento do sistema imunológico. Pesquisadores em Fisiologia e Imunologia necessitam ser orientados por estas influências comportamentais e sociais para garantir um controle adequado de seus próprios estudos.

\section{Comportamento Animal e meio ambiente, conservação e manejo de recursos naturais}

1. O comportamento dos animais freqüentemente fornece os primeiros indícios de degradação ambiental. Mudanças em comportamentos sexuais e em outros comportamentos ocorrem muito mais cedo e em níveis mais baixos de distúrbio ambiental do que alterações no padrão reprodutivo e no tamanho de populações. Se esperarmos até que o número de animais numa população diminua, poderá ser muito tarde para tomar medidas que salvem o ambiente. Estudos de comportamento no ambiente natural são vitais para proporcionar as bases para futuros monitoramentos ambientais. Por exemplo, a Agência de Proteção Ambiental dos Estados Unidos usa alterações comportamentais no deslocamento de pequenos peixes de água doce como um indicador de possível poluição por pesticida.

2. Pesquisas básicas, realizadas por Arthur Hasler, sobre a migração de salmões à nascente onde eclodiram, iniciaram-se há 40 
anos, e têm nos ensinado muito sobre os mecanismos da migração. Essas informações também têm sido importantes na preservação da indústria do salmão no noroeste do Pacífico e as aplicações dos resultados de Hasler levaram ao desenvolvimento de indústria de pesca do salmão nos Grandes Lagos. A pesquisa básica sobre o Comportamento Animal pode ter importantes implicações econômicas.

3. Estudiosos do Comportamento Animal têm descrito variáveis envolvidas na reprodução de insetos e localização de plantas hospedeiras, levando ao desenvolvimento de feromônios não-tóxicos para o controle de pestes, evitando dessa forma o uso de pesticidas tóxicos. A compreensão da relação presa-predador pode levar à introdução de predadores naturais de determinadas espécies de presas.

4. O conhecimento do comportamento de procura de alimento (forrageio) em abelhas, pode ser aplicado a mecanismos de polinização que, por sua vez, são importantes na reprodução e propagação de plantas.

5. O conhecimento do comportamento de forrageio dos animais pode levar à compreensão da regeneração florestal. Muitos animais atuam como dispersores de sementes sendo, portanto, essenciais para a propagação de espécies de árvores e para a preservação do hábitat.

6. A conservação de espécies ameaçadas de extinção requer que nós saibamos bastante sobre o comportamento natural dessas espécies (padrões migratórios, tamanho de território, interações com outros grupos, demandas de forrageio, comportamento reprodutivo, comunicação etc.) para criar reservas e medidas efetivas de proteção. A relocação ou reintrodução de animais (tal como no caso do micoleão dourado) não é possível sem um conhecimento detalhado da história natural da espécie. Com a crescente importância dos programas ambientais e manejo pelo homem de populações de espécies raras, tanto no cativeiro quanto no ambiente natural, a pesquisa do comportamento aumenta em sua relevância. Muitos conservacionistas de renome têm um conhecimento considerável sobre o Comportamento Animal ou Ecologia Comportamental.

7. Estudos básicos sobre o comportamento reprodutivo levaram ao aperfeiçoamento de técnicas de criação e reprodução em cativeiro 
de micos-leões dourados, Saguinus oedipus ${ }^{3}$, e muitas outras espécies ameaçadas de extinção. Criadouros que ignoram o comportamento reprodutivo natural da espécie são geralmente mal sucedidos.

\section{Comportamento Animal e bem-estar animal}

1. Nossa sociedade tem aumentado a atenção em relação ao bemestar de animais de pesquisa e de exposições. Nos Estados Unidos, a lei requer, por parte dos criadouros, a realização de exercícios para cães e o bem-estar psicológico de primatas não-humanos. Bem-estar animal sem conhecimento prévio é impossível. Estudiosos do Comportamento Animal observam o comportamento e o bem-estar animal, tanto em laboratório quanto no campo. Nós temos dado pareceres técnicos sobre normas razoáveis e efetivas para o cuidado e o bem-estar de animais mantidos em cativeiro para fins de pesquisa.

2. O desenvolvimento adicional do bem-estar animal requer produção de conhecimento por parte de especialistas em Comportamento Animal. Para prover boas condições para animais de fazendas, reprodução de espécies ameaçadas de extinção, cuidado apropriado para animais de companhia, é necessária uma forte base de estudo do comportamento.

\section{Comportamento Animal e Educação em Ciência}

Muitos dos membros da Animal Behavior Society (EUA) estão preocupados com a falta de informação científica do público em geral, o pequeno interesse que os estudantes têm pela ciência e o fato de que mulheres e grupos minoritários têm pouca representação na comunidade científica. Cursos de Comportamento Animal e Ecologia Comportamental prestam-se para atrair alunos para o estudo da biologia comportamental. Na Universidade de Wisconsin, em Madison (EUA), mais de 700 estudantes/ano cursam disciplinas em Comportamento Animal e Ecologia Comportamental nos Departamentos de Antropologia, Psicologia e Zoologia, embora nenhuma delas seja obrigatória. A Universidade Cornell (EUA) inscreve cerca de 400 alunos na disciplina de Introdução ao Comportamento, que é 
obrigatória para somente 60 a 70 desses alunos. As inscrições nessas disciplinas têm crescido cerca de $30 \%$ nos últimos três anos. Na Universidade de Stirling (Escócia), 75\% dos graduandos em Psicologia se inscrevem em uma disciplina não-obrigatória de Comportamento Animal. Na Universidade de Washington, Seattle (EUA), mais de 300 alunos se inscrevem, por período, em disciplinas básicas de Comportamento Animal. Situações similares podem ser encontradas em muitas outras universidades.

Para muitos alunos, especialmente as mulheres, essas disciplinas constituem-se em uma introdução ao estudo da Biologia Comportamental. Muitas alunas de graduação nos procuram para discutir sobre pós-graduação e carreira em pesquisa, após terem cursado disciplinas de Comportamento Animal. Dos nossos alunos de graduação e pós-graduação, 75\% ou mais são mulheres. Muitos alunos que se inscrevem em disciplinas de Comportamento Animal motivam-se para a carreira científica, conquanto apenas uma pequena parte pode nela prosseguir, por falta de oportunidades devido a limitações financeiras para a pesquisa.

Notas $\mid \begin{array}{ll}1 \quad & \text { Tradução de Arrilton Araújo e Maria Emí- } \\ & \text { lia Yamamoto (Departamento de Fisiolo- } \\ & \text { gia, Universidade Federal do Rio Grande } \\ & \text { do Norte). } \\ 2 & \text { Frans de Waal pesquisa comportamentos de } \\ & \text { reconciliação em primatas (N. do T.). } \\ 3 & \begin{array}{l}\text { Primata da mesma família do sagui, que } \\ \text { vive na floresta amazônica colombiana (N. } \\ \text { do T.). }\end{array}\end{array}$


Charles T. Snowdon, Ph. D. Sobre o autor em Psicologia pela Universidade da Pennsylvania (USA), pós-doutorado no Instituto de Ciências Neurológicas e Departamento de Biologia da Universidade da Pennsylvania, é professor do Departamento de Psicologia da Universidade de Wisconsin, Madison (USA) e Presidente da Animal Behavior Society (USA). Endereço para correspondência: 1202 West Johnson Street, WI $53706-$ 1696, USA.

E-mail: snowdon@macc.wisc.ed. 